OPEN ACCESS

Edited by:

Maria Jose Alvarez-Alonso,

Nebrija University, Spain

Reviewed by:

Valentina Lucia La Rosa,

University of Catania, Italy

Gianluca Serafini,

San Martino Hospital (IRCCS), Italy

*Correspondence:

Miguel Ipanaqué-Zapata mian.ipaza@gmail.com

Specialty section: This article was submitted to

Educational Psychology, a section of the journal

Frontiers in Psychology

Received: 22 September 2021 Accepted: 13 January 2022

Published: 23 February 2022

Citation:

Figueroa-Quiñones J, Cjuno J,

Machay-Pak D and

Ipanaqué-Zapata M (2022) Quality

of Life and Depressive Symptoms

Among Peruvian University Students

During the COVID-19 Pandemic.

Front. Psychol. 13:781561.

doi: 10.3389/fpsyg.2022.781561

\section{Quality of Life and Depressive Symptoms Among Peruvian University Students During the COVID-19 Pandemic}

\author{
Joel Figueroa-Quiñones ${ }^{1}$, Julio Cjuno ${ }^{2,3}$, Daniel Machay-Pak' and \\ Miguel Ipanaqué-Zapata ${ }^{1 *}$
}

${ }^{1}$ Instituto de Investigación, Capacitación y Desarrollo Psicosocial y Educativo: PSYCOPERU, Lima, Peru, ${ }^{2}$ Escuela Profesional de Psicología, Universidad Peruana Unión, Lima, Peru, ${ }^{3}$ Red Latinoamericana de Salud Mental en Pueblos Originarios, Lima, Peru

Objective: To determine the factors associated with quality of life and depressive symptoms in Peruvian university students during the COVID-19 pandemic.

Methods: Multicentre study in 1,634 students recruited by convenience sampling. The quality of life (QoL) was assessed with the European Quality of Life-5 Dimensions at three levels (EQ-5D-3L) and depressive symptoms with the Patient Health Questionnaire9 (PHQ-9). To assess factors associated with QoL and depressive symptoms, linear regressions and fitted regressions were used, with robust coefficients of variance information ( $\beta$ ).

Results: A 345 (21.1\%) reported problems in performing daily activities, 544 (33.3\%) reported pain and discomfort, 772 (47.2\%) were moderately/very anxious or depressed. Furthermore, 207 (12.7\%) had moderate-severe and severe depressive symptoms. Men reported better QoL than women ( $\beta$ : 3.2; 95\% Cl: 1.1, 5.4; $p=0.004$ ) and fewer depressive symptoms ( $\beta$ : $-0.7 ; 95 \% \mathrm{Cl}$ : $-1.3,-0.2 ; p=0.011)$. Ayacucho's residents had more depressive symptoms than Ancash's residents ( $\beta$ : 0.8; 95\% Cl: 0.1 , $1.5 ; p=0.022)$ and Piura's residents had fewer depressive symptoms than Ancash's residents $(\beta:-1.195 \% \mathrm{Cl}:-1.8,-0.3, p=0.005)$. Students who left home during quarantine reported more depressive symptoms ( $\beta$ : $0.7,95 \% \mathrm{Cl}: 0.2,1.2, p=0.006)$.

Conclusion: Problems performing daily activities, pain and discomfort, as well as mild to severe depressive symptoms were found in more than three-quarters of the sample. Authorities could consider depression care to improve quality of life in regions where high rates of infection occurred during the pandemic.

Keywords: quality of life, depressive symptoms, student, university, COVID-19, pandemic, Peru

\section{INTRODUCTION}

Coronavirus disease (COVID-19), classified as a pandemic by the World Health Organization (WHO), is a public health problem that has affected the entire world population. The disease has signs and symptoms similar to those of a common cold, but its complication in at-risk patients can be fatal (World Health Organization, 2020a). In September 2021, it had infected more than 200 
million people worldwide and caused more than four million deaths (World Health Organization, 2020b). Latin America has been one of the most affected cities, with more than 40 million cases of COVID-19 and 1,477,000 deaths (Pan American Health Organization, 2020).

Measures to control the spread of COVID-19, such as a state of national emergency and mandatory social isolation (confinement) were declared, have led to changes in people's life routines that could affect their mental health (Brooks et al., 2020; Rajkumar, 2020). A recent review study in China and Singapore reported the prevalence of anxiety and depressive symptoms in the population in ranges of $6-50 \%$ and $14-48 \%$, respectively (Pappa et al., 2020). Factors such as low income, being a woman and being unemployed significantly impair mental health in times of a COVID-19 pandemic (Mejia et al., 2020; ParradoGonzález, 2020). For example, in low-income countries such as Ethiopia, the prevalence of depressive and anxiety symptoms has been reported to be 46.2 and $48.1 \%$, respectively (Necho et al., 2020). Similarly, the COVID-19 pandemic has hurt the quality of life of these populations. A study with the Bangladeshi residents found that more than $50 \%$ of respondents had decreased quality of life, mainly due to difficulties in meeting their basic needs, loss of jobs and barriers to accessing education (Mondal et al., 2021). A study in China found that $41.3 \%$ of people had depressive symptoms and a significantly lower quality of life (Ma et al., 2020). In Latin America, there is little literature on assessing the association between quality of life and depressive symptoms in times of pandemic (COVID-19), with only one study in a Brazilian population reporting high levels of depressive symptoms $(41.9 \%)$ and anxiety symptoms $(29.0 \%)$, which were associated with poorer quality of life (Vitorino et al., 2021).

In education, the rapid transmission of COVID-19 led to the suspension of face-to-face academic activities, affecting $91.3 \%$ of the global student population and 23.4 million higher education students in Latin America and the Caribbean, who had to adapt quickly to non-face-to-face education (Instituto Internacional para la Educación Superior en América Latina y el Caribe, 2020). A review study with more than 436,799 students from the United States and China found stress in 23\%, anxiety in $29 \%$, and depression in $37 \%$, so that the abrupt adaptation to virtual education may have deteriorated the quality of life and mental health in this population (Wang et al., 2021). In Bangladesh, a high percentage of university students with depressive (54.5\%) and anxious (42.9\%) symptoms were reported (Islam et al., 2020). Also, in Europe, there are studies in Greece of 1,000 university students who reported prevalences of $42.5 \%$ for anxiety, $74.3 \%$ for depression, $63.3 \%$ suicidal thoughts, and quality of life has worsened by $43.0 \%$ (Kaparounaki et al., 2020). In Italy, a study of 655 university students reported feelings of sadness (51.3\%), nervousness (64.6\%), irritability (57\%), difficulty concentrating (55.9\%), difficulty sleeping (54.5\%), eating disorders $(73.6 \%)$, tachycardia $(65 \%)$, and a tendency to cry (65\%) (Commodari et al., 2021).

Peru has been a country most affected by the COVID19 pandemic. The confinement affected the education of Peruvian students due to economic hardship and the digital divide (internet connectivity and computer use). This action led the government to implement economic policies for Peruvian families and the education sector, such as the issuance of economic bonds, educational credits, connectivity, and scholarships (Figallo et al., 2020; Contraloría General de la República, 2021). For example, the National Institute of Statistics and Informatics revealed that during 2020, monetary poverty of Peruvian households amounted to $30.1 \%$, increasing 10 percentage points from the previous year, affecting mainly $45.7 \%$ of the rural population and $26.0 \%$ of the urban population. Moreover, 85.7 and $82 \%$ of these poor households do not have a computer or Internet access, respectively (Instituto Nacional de Estadística e Informática, 2021), there are only studies before the COVID-19 pandemic in Peru where they reported low levels of quality of life and the presence of depressive symptoms in 52.2 and $24.6 \%$ of the university population, respectively (Kuong and Concha, 2017; Diaz-Godiño et al., 2019).

Given the above, there is little research in Latin America and non-existent in Peru on the evaluation of the quality of life (QoL) situation associated with depressive symptomatology and the associated factors of the same, in a population of university students in times of COVID-19, considering that the current pandemic situation generates a greater state of vulnerability (Puthran et al., 2016; Ribeiro et al., 2018), making it difficult to implement programmes and interventions to improve mental health and quality of life in the face of such a state of emergency (Figallo et al., 2020). Therefore, this study determined the factors associated with quality of life and depressive symptomatology in Peruvian university students during COVID-19.

\section{MATERIALS AND METHODS}

\section{Study Design}

We conducted a multicentre cross-sectional study of students at a private university in four regions of Peru (Ancash, Ayacucho, Lima, and Piura), with large student populations and entrenched socio-cultural differences between July and August 2020.

\section{Participants}

The study participants were 1,634 university students from four regions of Peru (Ancash, Ayacucho, Lima, and Piura), which were obtained from a non-probabilistic convenience sampling, with an online survey sent through social networks (WhatsApp and email), where informed consent was presented through the presentation of the problem and the objective of the study, to subsequently decide the option to voluntarily participate in filling out the questionnaire; those who agreed to participate in the study answered all the questions of the data collection instrument. The eligibility criteria for a student to participate in the study were as follows: (i) Being over 18 years of age, (ii) Residing in the pandemic crisis within the regions of Peru, where the study was conducted, and (iii) Students studying at the undergraduate level within the private university where the data were collected. On the other hand, the only exclusion criterion was to exclude participants who did not fully answer the questions in the questionnaires. However, it is important to mention that it was impossible to take into account the 
evaluation of previous psychiatric comorbidities, because at the time of data collection, it was not feasible in Peru due to the restrictions established.

\section{Procedures}

The electronic survey generated for the study followed the quality improvement recommendations for web-based surveys based on the Checklist for reporting results of Internet e-surveys (CHERRIES) (Eysenbach, 2012).

The development and data collection of the electronic instrument was carried out through the Survey Monkey virtual platform (Survey Monkey, 1999). Initially, this electronic instrument consisted of an introduction explaining the composition of the work team, the objectives of the study, anonymity, confidentiality of the data and the use of the information for scientific purposes only. Subsequently, students were given informed consent to continue with the survey. The time to complete the questionnaire was $15 \mathrm{~min}$.

The survey was promoted through emails and university student study groups (WhatsApp), between the period of July and August 2020. Participants were free to opt out of the questionnaire at any time, without explanation, and were not asked to identify themselves due to the confidentiality of the information. Finally, all the surveys completed by university students were securely stored using a passwordprotected database.

\section{Variables}

The primary variables were quality of life (QoL) and depressive symptomatology in university students from four regions of Peru. The QoL variable was measured through the European Quality of Life-5 Dimensions questionnaire in three levels (EQ5D-3L) (EuroQol, 2017), composed of five items that respond to five dimensions (Mobility, Self-care, Daily activities, Pain or Discomfort, Depression or Anxiety), with three levels of response (absence, moderate presence, and severe presence). It also has a visual analog scale (EQ-VAS) that reports current life status on a range from 0 (worst status) to 100 (best status), this last indicator of QoL. We used the cultural adaptation of the EQ-5D-3L translated into Spanish available for Peru, carried out by the EuroQol Group, which was responsible for the original instrument and its theoretical validation (Herdman et al., 2003). The EQ-5D-3L is a widely used instrument worldwide to assess quality of life. Some studies have conducted psychometric validity of this instrument, reporting adequate indicators of discriminant validity (Shannon's $\mathrm{H}^{\prime}: 0.47$ and 0.98 ) and good reliability (weighted Kappa ${ }_{\mathrm{w}} \mathrm{K}: 0.39-0.93$ ); however, this type of validation was performed on the original version (Buchholz et al., 2018). On the other hand, there are few psychometric validation studies in the Spanish-speaking version using the general and/or clinical population (García-Gordillo et al., 2015). In Peru, this type of validation has not yet been conducted; however, several studies in the country report similar and consistent results within this geographical context (Taype-Rondan et al., 2017; FigueroaQuiñones et al., 2019).

The Patient Health Questionnaire-9 (PHQ-9) was used for the variable depressive symptoms. It is a nine-item self-administered questionnaire with five response levels according to the frequency of depressive symptoms in the last 2 weeks: not at all, several days, more than half of the days, and almost every day. The total score is within the range of 0 to 27 points. Depressive symptoms are also reported according to severity levels: minimal (0-4), mild (5-9), moderate (10-14), moderate-severe (15-19), and severe (20-27) (Spitzer et al., 1999; Kroenke et al., 2001; Cameron et al., 2008). This questionnaire has been validated in the Peruvian population, presenting indicators of psychometric properties through confirmatory factor analysis (CFI $=0.936$, TLI $=0.914$, RMSEA $=0.089$ and SRMR $=0.039)$ and reliability of Cronbach's Omega and Alpha indicators $(\omega=0.87$ and $\alpha=0.87)$, interpreted in such a way because many indicators such as CFI and TLI are close to 0.90; the RMSEA at 0.08 and the SMRM is lower than 0.08; while, for reliability, the values of Cronbach's omega and alpha indexes are higher than the optimal point $(0.80)$ (Villarreal-Zegarra et al., 2019).

The covariates that participated in the study were age (in tertiles), sex (male or female), regions of residence (Ancash, Ayacucho, Lima, and Piura), marital status (single, separated, widowed, divorced, and married or partner), occupation (studying and working or only working), left home during quarantine (no and yes), decrease in family income in quarantine (no and yes), lives alone (no and yes) and family with chronic disease (no and yes).

\section{Data Analysis}

A descriptive analysis was presented using measures of central tendency and dispersion (for numerical variables) and absolute frequencies (for categorical variables). We performed linear regression with robust variance reporting crude, adjusted model with coefficients $(\beta)$ and their 95\% confidence intervals (CI95\%) to evaluate the association of the factors associated with the EQVAS (quality of life) and PHQ-9 (depressive symptoms) scores. In all cases, variables that obtained a $p<0.20$ in the crude model were included in the adjusted model. Analyses were performed in Stata v15.0 statistical software (StataCorp, 2017).

\section{Ethics Statement}

This study was reviewed and approved by the Ethics Committee of the Universidad Católica Los Ángeles de Chimbote (Los Angeles de Chimbote Catholic University). In addition, the study was anonymous and voluntary, so it does not pose a risk to participants who accepted their participation with the onlineinformed consent. With the approval of the ethics committee and the ethical steps followed for data collection, we sought to ensure compliance with the National Commission for the Protection of Human Subjects of Biomedical and behavioral Research (Commission for Protection of Human Subjects of Biomedical and Behavioral Research, 1978).

\section{RESULTS}

The 1,825 participants were initially recruited, of which 65 did not agree to participate in the study and 126 did not complete the entire survey; therefore, only 1,634 (89.5\%) university students 
participated in the study. The participants were distributed according to the region of residence: $712(43.6 \%)$ are from Ayacucho, 347 (21.2\%) from Ancash, 342 (20.9\%) from Piura and, 233 (14.3\%) from Lima (Table 1).

Participants had a median age of 24 years (interquartile range: 20-30 years), 1,146 (70.1\%) were women, 1,270 (77.7\%) reported being single, separated, widowed, or divorced. University students studying and working at the same time were 842 (51.5\%) with a significant prevalence in Lima. 879 (53.8\%) of the university students reported leaving home during quarantine, $1,511(92.5 \%)$ had a decrease in family income, 1,502 (91.9\%) declared not living alone and 959 (58.69\%) had a family member with a chronic disease (Table 1).

On the quality of life during the pandemic, $345(21.1 \%)$ reported problems in carrying out daily activities, 544 (33.3\%) reported pain and discomfort and 667 (40.8\%) reported being moderately anxious or depressed and 105 (6.4\%) reported being severe anxious and depressed (Table 2).

In addition, $741(45.4 \%)$ students had mild and moderate depressive symptoms, while 207 (12.7\%) had moderate-severe and severe depressive symptoms (Table 3 ).

The univariate analysis reported that during the COVID19 pandemic, being male and residing in Lima or Piura were associated with higher EQ-VAS (quality of life) scores; whereas, being between 22 and 27 years of age, is dedicated only to study, residing in the Ayacucho region, leaving home during quarantine, suffering a decrease in family income during quarantine, having a family member with chronic illness and depressive symptom scores decreased QoL scores (Table 4).

In multivariate analysis, men reported better quality of life than women ( $\beta$ : $3.2 ; 95 \% \mathrm{CI}: 1.1,5.4 ; p=0.004)$, and men also had fewer depressive symptoms $(\beta:-0.7 ; 95 \% \mathrm{CI}:-1.3,-0.2$; $p=0.011)$. Those residing in Ayacucho had more depressive symptoms than those residing in Ancash ( $\beta$ : $0.8 ; 95 \%$ CI: 0.1 , $1.5 ; p=0.022$ ) and those residing in Piura had fewer depressive symptoms than those residing in Ancash $(\beta:-1.1 ; 95 \% \mathrm{CI}:-1.8$, $-0.3 ; p=0.005)$ and, finally, students who left home during quarantine had more depressive symptoms than those who did not ( $\beta$ : 0.7; 95\% CI: $0.2 ; 1.2 ; p=0.006)$ (Table 4 ).

On the other hand, factors associated with PHQ-9 scores (depressive symptoms) reported that all variables were significantly associated. However, after adjusting the model with all variables, we were find that these were still significant: residing in the region of Ayacucho, leaving home in quarantine, and having a family member with chronic disease have higher scores for depressive symptoms; while being male, residing in the region of Piura and higher QoL score decrease scores for depressive symptoms. Our positive relationship results concerning depressive symptom scores show that university students residing in Ayacucho have higher scores compared to

TABLE 1 | Characteristics of the populations studied.

\begin{tabular}{|c|c|c|c|c|c|}
\hline Variables & Total $(n=1634)$ & Ancash $(n=347)$ & Ayacucho $(n=712)$ & Lima $(n=233)$ & Piura $(n=342)$ \\
\hline Age: Median (IQR) & $24(20-30)$ & $22(20-27)$ & $24(21-30)$ & $22(19-28)$ & $30(21-42)$ \\
\hline \multicolumn{6}{|l|}{ Age in tertiles (years) } \\
\hline $16-21$ & $575(35.2)$ & $151(43.5)$ & $198(27.8)$ & $66(28.3)$ & $160(46.8)$ \\
\hline $22-27$ & $524(32.1)$ & $110(31.7)$ & $282(39.6)$ & $36(15.5)$ & $96(28.1)$ \\
\hline 28-65 & $535(32.7)$ & $86(24.8)$ & $232(32.6)$ & $131(56.2)$ & $86(25.1)$ \\
\hline \multicolumn{6}{|l|}{ Sex } \\
\hline Female & $1,146(70.1)$ & $259(74.6)$ & $491(69.0)$ & $145(62.2)$ & $251(73.4)$ \\
\hline Male & 488 (29.9) & $88(25.4)$ & $221(31.0)$ & $88(37.8)$ & $91(26.6)$ \\
\hline \multicolumn{6}{|l|}{ Marital status } \\
\hline Singer/separate/widowed/divorced & $1,270(77.7)$ & $282(81.3)$ & $555(77.9)$ & $156(66.9)$ & $277(81.0)$ \\
\hline Married/partner & $364(22.3)$ & $65(18.7)$ & $157(22.1)$ & $77(33.1)$ & $65(19.0)$ \\
\hline \multicolumn{6}{|l|}{ Occupation } \\
\hline Study and work & $842(51.5)$ & $153(44.1)$ & $392(55.1)$ & $146(62.7)$ & $151(44.2)$ \\
\hline Only study & $792(48.5)$ & $193(55.9)$ & $320(44.9)$ & $87(37.3)$ & $191(55.8)$ \\
\hline \multicolumn{6}{|l|}{ Left home in quarantine } \\
\hline No & $755(46.2)$ & $120(34.6)$ & $332(46.6)$ & $113(48.5)$ & $190(55.6)$ \\
\hline Yes & $879(53.8)$ & $227(65.4)$ & $380(53.4)$ & $120(51.5)$ & $152(44.4)$ \\
\hline \multicolumn{6}{|c|}{ Decreasing family financial income in quarantine } \\
\hline No & $123(7.5)$ & $25(7.2)$ & $39(5.5)$ & $27(11.6)$ & $32(9.4)$ \\
\hline Yes & $1,511(92.5)$ & $322(92.8)$ & $673(94.5)$ & $206(88.4)$ & $310(90.6)$ \\
\hline \multicolumn{6}{|l|}{ Lives alone } \\
\hline No & $1,502(91.9)$ & $317(91.3)$ & $636(89.3)$ & $214(91.9)$ & $335(97.9)$ \\
\hline Yes & $132(8.1)$ & $30(8.7)$ & $76(10.7)$ & $19(8.1)$ & $7(2.1)$ \\
\hline \multicolumn{6}{|l|}{ Family member with disease } \\
\hline No & $959(58.7)$ & $197(56.8)$ & $461(64.8)$ & $116(49.8)$ & $185(54.1)$ \\
\hline Yes & 675 (41.3) & $150(43.2)$ & $251(35.2)$ & $117(50.2)$ & $157(45.9)$ \\
\hline
\end{tabular}

$I Q R$, interquartile range. 
TABLE 2 | Quality of life in Peruvian university students during the COVID-19 pandemic.

\begin{tabular}{lc}
\hline Quality of life & $\mathbf{n}(\%)$ \\
\hline Mobility & \\
I have no problems walking & $1,526(93.4)$ \\
I have some problems walking & $91(5.6)$ \\
I have to be in bed & $17(1.0)$ \\
Personal care & \\
I have no problems with the personal care & $1,558(95.4)$ \\
I have some problems washing myself & $69(4.2)$ \\
I'm unable to wash or dress myself & $7(0.4)$ \\
Daily activity & \\
I have no problems in performing my activities & $1,284(78.6)$ \\
I have some problems to performing my activities & $345(21.1)$ \\
I'm unable to performing my activities. & $5(0.3)$ \\
Pain or discomfort & \\
I have no pain or discomfort & $1,052(64.4)$ \\
I have moderate pain or discomfort & $544(33.3)$ \\
I have a lot of pain or discomfort & $38(2.3)$ \\
Anxiety or depression & \\
I'm not anxious or depressed & $662(52.8)$ \\
I'm moderately anxious or depressed & $105(6.4)$ \\
I'm very anxious or depressed & \\
EQ-VAS total & $76.0(25.6)$ \\
\hline Median (SD) & \\
\hline
\end{tabular}

SD, standard deviation.

TABLE 3 | Depressive symptoms in Peruvian university students during the COVID-19 pandemic.

\begin{tabular}{lc}
\hline Depressive symptoms & $\mathbf{n}(\%)$ \\
\hline Depression & \\
Minimum & $686(42.0)$ \\
Mild & $475(29.1)$ \\
Moderate & $266(16.3)$ \\
Moderate-severe & $132(8.1)$ \\
Severe & $75(4.59)$ \\
\hline
\end{tabular}

those residing in Ancash $(\beta=0.8,95 \% \mathrm{CI}=0.1$ to 1.5$)$, those residing in Ancash $(\beta=0.8,95 \% \mathrm{CI}=0.1$ to 1.5$)$ and those residing in Piura $(\beta=0.8,95 \% \mathrm{CI}=0.1$ to 1.5$)$, those who were quarantined compared to those who were not $(\beta=0.7,95 \%$ $\mathrm{CI}=0.2$ to 1.2 ) and having a family member with a chronic illness presented higher scores in depressive symptomatology compared to those who did not have family members with an illness ( $\beta=1.5,95 \% \mathrm{CI}=1.0$ to 2.1 ); the latter factor being the biggest problem. Meanwhile, concerning the negative relationship, men had lower scores than women $(\beta=-0.7,95 \% \mathrm{CI}=-1.3$ to -0.2$)$, with residents of the region of Piura having lower scores than those residing in Ancash $(\beta=-1.1,95 \% \mathrm{CI}=-1.8$ to -0.3$)$. Finally, the quality of life scores decreased by 1 quality of life points increased by 0.1 points in depressive symptoms $(\beta=-0.1$, 95\% CI $=-0.2$ to -0.1 ) (Table 4).

\section{DISCUSSION}

University students in relation to QoL during the pandemic reported some problems in performing daily activities 345 (21.1\%), pain and discomfort in $544(33.3 \%)$ and reported being moderately anxious or depressed in 667 (40.8\%) and severe anxious and depressed in 105 (6.4\%). Furthermore, the PHQ9 reported that $741(45.4 \%)$ had mild and moderate depressive symptoms, while 207 (12.7\%) had moderate-severe and severe depressive symptoms. These results are consistent with the study conducted in Vietnamese university students during the COVID-19 pandemic, which reported greater impairment in the anxiety/depression and pain/discomfort dimensions of QoL (Tran et al., 2020). Another study with young Chinese adults reported similar impairment in QoL dimensions during the pandemic (Ping et al., 2020). These findings may possibly be due to bereavement over the death of students' family members, isolation and reduced physical activities (Hamid and Jahangir, 2020) and fear caused by overexposure to the media and the high lethality of the virus (Mejia et al., 2020), which may have increased symptoms of anxiety or depression. In addition, the long months of confinement resulted in constant exposure to stress and often manifested in pain and discomfort (EsquivelAcevedo et al., 2020). On the other hand, non-face-to-face education meant that the student had to sit in front of the computer for a long time, choosing postures that provided comfort, however, incorrect body postures could have generated pain and tension (Yang et al., 2020).

On the other hand, males reported better QoL than females ( $\beta$ : $3.2 ; 95 \%$ CI: $1.1,5.4 ; p=0.004$ ) and fewer depressive symptoms $(\beta:-0.7 ; 95 \% \mathrm{CI}:-1.3,-0.2 ; p=0.011)$. This result could be explained by several factors; for example, women nowadays have more responsibilities in the work environment and during confinement the with family support needs (e.g., family caregivers) has increased, leading to more stress, and depression (Verma and Mishra, 2020; Wang et al., 2020). Moreover, confinement as a measure to prevent the spread of COVID-19 and the inability to interact socially with peers has a negative impact on mental health (Brooks et al., 2020; Palgi et al., 2020). Likewise, the new normality that was accompanied by sedentary behavior adopted by students due to non-face-toface education and financial insecurity for educational expenses may have increased depressive symptoms in university students (Huckins et al., 2020; Islam et al., 2020), as well as; it may have been a reaction associated with confinement and habit changes (Vásquez et al., 2020).

Residents in Ayacucho presented greater depressive symptomatology than those in Ancash ( $\beta$ : $0.8 ; 95 \%$ CI: 0.1 ; $1.5 ; p=0.022)$ and residents in Piura had less depressive symptomatology than those in Ancash ( $\beta$ :-1.1 95\% CI: -1.8 ; $-0.3 ; p=0.005)$. This result could be explained by the fact that during the evaluation months of our study, the rate of COVID-19 infections and deaths in Piura had decreased, while in Ayacucho, in rural Peru, it was at its highest peak (Plataforma digital única del Estado Peruano, 2020).

In addition, students who left home during the quarantine were find to have greater depressive symptoms than those who 
TABLE 4 | Factors associated with quality of life and depressive symptoms in Peruvian university students during the COVID-19 pandemic.

\begin{tabular}{|c|c|c|c|c|c|c|c|c|}
\hline \multirow[t]{2}{*}{ Variables } & \multicolumn{4}{|c|}{ Quality of life } & \multicolumn{4}{|c|}{ Depressive symptoms } \\
\hline & $\begin{array}{c}\text { Crude } \\
\beta(\mathrm{IC95 \% )}\end{array}$ & $\mathbf{p}$ & $\begin{array}{c}\text { Full } \\
\beta(\text { IC95\%) }\end{array}$ & p & $\begin{array}{c}\text { Crude } \\
\beta(\mathrm{IC} 95 \%)\end{array}$ & p & $\begin{array}{c}\text { Full } \\
\beta(\text { IC95\%) }\end{array}$ & p \\
\hline \multicolumn{9}{|l|}{ Age } \\
\hline $16-21$ & \multicolumn{4}{|c|}{ REF } & \multicolumn{4}{|c|}{ REF } \\
\hline $22-27$ & $-3.4(-6.5 ;-0.3)$ & 0.032 & $-2.3(-5.0 ; 0.4)$ & 0.101 & $0.51(-0.2 ; 1.2)$ & 0.170 & $-0.1(-0.6 ; 0.6)$ & 0.986 \\
\hline Female & \multicolumn{4}{|c|}{ REF } & \multicolumn{4}{|c|}{ REF } \\
\hline Male & $7.0(4.5 ; 9.4)$ & 0.000 & $3.2(1.1 ; 5.4)$ & 0.004 & $-1.7(-2.3 ;-1.1)$ & 0.000 & $-0.7(-1.3 ;-0.2)$ & 0.011 \\
\hline \multicolumn{9}{|l|}{ Marital status } \\
\hline Singer/separated/widowed/divorced & \multicolumn{4}{|c|}{ REF } & \multicolumn{4}{|c|}{ REF } \\
\hline Married/partner & $1.7(-1.2 ; 4.5)$ & 0.239 & - & - & $-1.1(-1.7 ;-0.4)$ & 0.002 & $-0.5(-1.2 ; 0.1)$ & 0.112 \\
\hline \multicolumn{9}{|l|}{ Places of residence } \\
\hline Ancash & \multicolumn{4}{|c|}{ REF } & \multicolumn{4}{|c|}{ REF } \\
\hline Ayacucho & $-3.5(-6.8 ;-0.2)$ & 0.040 & $-2.1(-4.8 ; 0.8)$ & 0.151 & $0.9(0.1 ; 1.7)$ & 0.039 & $0.8(0.1 ; 1.5)$ & 0.022 \\
\hline Lima & $4.0(0.1 ; 7.9)$ & 0.043 & $0.6(-2.8 ; 4.1)$ & 0.719 & $-1.6(-2.5 ;-0.6)$ & 0.001 & $-0.7(-1.5 ; 0.2)$ & 0.116 \\
\hline Piura & $3.6(0.0 ; 7.3)$ & 0.049 & $0.1(-3.0 ; 3.3)$ & 0.933 & $-1.6(-2.5 ;-0.8)$ & 0.000 & $-1.1(-1.8 ;-0.3)$ & 0.005 \\
\hline \multicolumn{9}{|l|}{ Went out of the house during quarantine } \\
\hline No & \multicolumn{4}{|c|}{ REF } & \multicolumn{4}{|c|}{ REF } \\
\hline Yes & $-3.2(-5.7 ;-0.7)$ & 0.012 & $-0.9(-3.1 ; 1.2)$ & 0.396 & $1.1(0.5 ; 1.7)$ & 0.000 & $0.7(0.2 ; 1.2)$ & 0.006 \\
\hline \multicolumn{9}{|c|}{ Decreasing family financial income in quarantine } \\
\hline No & \multicolumn{4}{|c|}{ REF } & \multicolumn{4}{|c|}{ REF } \\
\hline Yes & $-8.1(-11.6 ;-4.6)$ & 0.000 & $-3.4(-6.5 ;-0.3)$ & 0.034 & $1.9(0.8 ; 2.9)$ & 0.000 & $0.7(-0.2 ; 1.6)$ & 0.141 \\
\hline
\end{tabular}

${ }^{+}$Depressives Symptoms was obtained from the Patient Health Questionnaire-9 (PHQ-9) total score. ${ }^{++}$Quality of life was obtained from the Visual Analog Scale (EQ-VAS).

were compliant with staying at home $(\beta: 0.7 ; 95 \%$ CI: $0.2,1.2$; $p=0.006)$. Possibly a reason why university students were forced to leave home was the loss of family income, which implies difficulties in accessing treatment, medication and living expenses, affecting the quality of life and leading to the onset of some depressive symptoms (Kretchy et al., 2020; Ping et al., 2020; Tran et al., 2020). A study in China with university students also reported mental health problems due to COVID-19 (Wang and Zhao, 2020). It is important to note that other studies show that these mental health problems are more prominent in students within the adolescent stage (Commodari and La Rosa, 2020) and most likely the entire increase is due to the COVID-19 pandemic; however, the extent of influence of the changes themselves has so far not been determined (i.e., mood and mental impairment) o of this stage in mental health reports (Commodari and La Rosa, 2020). Another reason may have been that this age group, according to case-fatality reports, had a lower mortality risk than adults and the elderly, but the fear of bringing the virus home and infecting their family members may have generated the depressive symptoms (Figueroa-Quiñones and Ipanaqué-Neyra, 2020; Johnson et al., 2020). Depressive symptoms influence and impact the quality of life of university students (Gan and Yuen Ling, 2019).

The strength of our study is that it is the first study to report up-to-date evidence on the quality of life and mental health status of university students in Peru after the confinement of the COVID-19 pandemic. However, the study has some limitations. Due to the confinement by COVID-19, is the non-probabilistic nature of the sampling, which affects the representativeness of the study sample and the probable impossibility of generalizing the results obtained; however, a significant sample size was achieved in different cities of Peru, which produces consistent evidence of university students, and the results obtained were similar to other studies conducted (Chang et al., 2020; Tran et al., 2020). Another 
limitation of the study was that it did not take into account the inclusion of any restrictions on particular clinical characteristics, the subjects may have had previous psychiatric comorbidities, so the problems found may possibly be slightly inaccurate, and it is recommended that future studies include previous history or mental health treatment. Likewise, the instrument used (EQ5D-3L) to assess psychometric quality of life was not validated in Peru, however, this instrument has been used in other studies and populations in Peru (Taype-Rondan et al., 2017; FigueroaQuiñones et al., 2019), moreover, it was translated into Spanish by the EuroQol Group and has been adapted in other countries and languages (EuroQol, 2017).

\section{CONCLUSION}

It is concluded that university students reported some problems in performing daily activities, pain and discomfort, as well as mild to severe depressive symptoms in more than three quarters of the sample in relation to their QoL during the pandemic. Therefore, our health authorities also consider psychological interventions to reduce depressive symptoms and improve QoL. On the other hand, men reported better QoL than women and lower depressive symptoms. The female students would be a priority in the Peruvian university population for managing depressive symptoms. In addition, Ayacucho's residents had higher depressive symptoms than Ancash's residents and Piura's residents reported lower depressive symptoms than Ancash's residents. Health authorities might therefore consider addressing depression in pandemics in settings with high infection rates of infection are reported. A clear example is the professional associations of psychology in the cities of Peru most affected by depression should work in coordination with the health and university sectors to design plans and actions for prevention, detection and subsequent emotional support for their students with depressive symptomatology through virtual platforms (electronic devices, hotlines and internet) and to be able to provide immediate professional help to students affected during COVID-19.

It has also been found that students who left home during quarantine had more depressive symptoms than those who did not. Therefore, education authorities also provide contingency plans for students in pandemic situations, as the lack of resources often forces them to leave home. Universities in Peru could mitigate such depressive symptoms in students by generating a more effective promotion of care programmes with a psychological specialist, while it is true that such attention promotion exists, the impact on students is mostly low. The

\section{REFERENCES}

Brooks, S. K., Webster, R. K., Smith, L. E., Woodland, L., Wessely, S., Greenberg, N., et al. (2020). The psychological impact of quarantine and how to reduce it: Rapid review of the evidence. Lancet 395, 912-920. doi: 10.1016/S01406736(20)30460-8

Buchholz, I., Janssen, M. F., Kohlmann, T., and You-Shan, F. (2018). A Systematic Review of Studies Comparing the Measurement Properties of the Three-Level increase in student scholarships and the reduction of pension costs by universities and/or subsidies and economic bonuses for families by the government could also help reduce students' worries about paying for their studies, considering that in an undeveloped country, many university students must study and work simultaneously to survive and achieve their academic goals.

Furthermore, suicidal tendencies are prevalent behavior in subjects with anxiety/depression problems and are often complicated by underlying pathophysiological factors and due to our findings in the current context by COVID-19 we believe that it might increase the risk for subjects' mental health and quality of life. Therefore, mental health authorities should plan assessments, interventions and treatments in clinical practice for affected students.

\section{DATA AVAILABILITY STATEMENT}

The datasets presented in this study can be found in online repositories. The names of the repository/repositories and accession number(s) can be found below: https://doi.org/10. 7910/DVN/93WCEZ.

\section{ETHICS STATEMENT}

The studies involving human participants were reviewed and approved by the Research Ethics Committee of Los Angeles Catholic University of Chimbote. The participants provided their written informed consent to participate in this study.

\section{AUTHOR CONTRIBUTIONS}

JF-Q carried out the administration of the manuscript. MI-Z performed the methodology, data retention, formal analysis, and supervision of the manuscript. JF-Q and MI-Z were responsible for the visualization and validation of the manuscript. JC was responsible for the acquisition of funds for the manuscript. JF-Q, JC, DM-P, and MI-Z were responsible for the preparation of the first report and the final version of the original manuscript. All authors contributed to the article and approved the submitted version.

\section{FUNDING}

This study was funded by the Universidad Peruana Unión (UPU).

and Five-Level Versions of the EQ-5D. PharmacoEconomics 36, 645-661. doi: 10.1007/s40273-018-0642-5

Cameron, I. M., Crawford, J. R., Lawton, K., and Reid, I. C. (2008). Psychometric comparison of PHQ-9 and HADS for measuring depression severity in primary care. Br. J. General Pract. 58, 32-36. doi: 10.3399/bjgp08X263794

Chang, J., Yuan, Y., and Wang, D. (2020). Mental health status and its influencing factors among college students during the epidemic of COVID-19. J. Southern Med. Univers. 40, 171-176. doi: 10.12122/j.issn.1673-4254.2020.02.06 
Commission for Protection of Human Subjects of Biomedical and Behavioral Research (1978). The Belmont report: ethical principles and guidelines for the protection of human subjects of research. DHEW Publication No. (OS) 78-0012. Washington, DC: Government Printing Office.

Commodari, E., and La Rosa, V. L. (2020). Adolescents in quarantine during COVID-19 pandemic in Italy: perceived health risk, beliefs, psychological experiences and expectations for the future. Front. Psychol. 11:2480. doi: 10. 3389/fpsyg.2020.55995

Commodari, E., La Rosa, V. L., Carnemolla, G., and Parisi, J. (2021). The psychological impact of the lockdown on Italian university students during the first wave of COVID-19 pandemic: psychological experiences, health risk perceptions, distance learning, and future perspectives. Mediterranean J. Clin. Psychol. 9:3009. doi: 10.13129/2282-1619/mjcp-3009

Contraloría General de la República (2021). Control en la pandemia por la COVID19. Informe de gestión del control gubernamental en la Emergencia Sanitaria a los 365 días. Bogotá: Contraloría General de la República.

Diaz-Godiño, J., Fernández-Henriquez, L., Peña-Pastor, F., Alfaro-Flores, P., Manrique-Borjas, G., and Mayta-Tovalino, F. (2019). Lifestyles, Depression, Anxiety, and Stress as Risk Factors in Nursing Apprentices: A Logistic Regression Analysis of 1193 Students in Lima, Peru. J. Environ. Public Health 2019:7395784. doi: 10.1155/2019/7395784

Esquivel-Acevedo, J. A., Sánchez-Guerrero, O., Ochoa-Palacios, R., MolinaValdespino, D., and Muñoz-Fernández, S. I. (2020). Estrés, respuestas emocionales, factores de riesgo, psicopatología y manejo del personal de salud durante la pandemia por COVID-19. Acta Pediatr. Mex. 41, 127-136.

EuroQol (2017). EQ-5D-3L User Guide. Available online at: https://euroqol.org/eq5d-instruments/eq-5d-31-about/ (accessed September 19, 2017).

Eysenbach, G. (2012). Correction: Improving the quality of web surveys The checklist for reporting the results of electronic surveys on the Internet (CHERRIES). J. Med. Internet Res. 2012:2042. / jmir.2042 doi: 10.2196

Figallo, F., González, M. T., and Diestra, V. (2020). Perú: Educación superior en el contexto de la pandemia por el COVID-19. Revista de Educación Superior en América Latina 2020:13404.

Figueroa-Quiñones, J., and Ipanaqué-Neyra, J. (2020). Pánico por COVID-19 y colapso de los sistemas sanitarios. Revista Cubana de Investigaciones Biomédicas 39:1064.

Figueroa-Quiñones, J., Cjuno, J., Ipanaqué-Neyra, J., Ipanaqué-Zapata, M., and Taype-Rondan, A. (2019). Calidad de vida de migrantes venezolanos en dos ciudades del norte del Perú. Revista Peruana de Medicina Experimental y Salud Pública 36, 383-391. doi: 10.17843/rpmesp.2019.363.4517

Gan, G. G., and Yuen Ling, H. (2019). Anxiety, depression and quality of life of medical students in Malaysia. Med. J. Malaysia 74, 57-61.

García-Gordillo, M. A., Del Pozo-Cruz, B., Adsuar, J. C., Cordero-Ferrera, J. M., Albellán-Perpiñán, J. M., and Sánchez-Martínez, F. I (2015). Validación y comparación de instrumentos EQ-5D-3L y SF-6D en una muestra de población española con enfermedad de Parkinson. Nutrición 32, 2808-2821.

Hamid, W., and Jahangir, M. S. (2020). Dying, Death and Mourning amid COVID19 Pandemic in Kashmir: A Qualitative Study. OMEGA J. Death Dying 0, 1-26. doi: $10.1177 / 0030222820953708$

Herdman, M., Fox-Rushby, J., Rabin, R., Badia, X., and Selai, C. (2003). "Producing other language versions of the EQ-5D," in The measurement and valuation of health status using EQ-5D: A European Perspective, eds R. Brooks, R. Rabin, and F. de Charro (Dordrecht: Kluwer), 183-190. doi: 10.1007/978-94-017-0233-1_ 11

Huckins, J. F., DaSilva, A. W., Wang, W., Hedlund, E., Rogers, C., Nepal, S. K., et al. (2020). Mental Health and Behavior of College Students During the Early Phases of the COVID-19 Pandemic: Longitudinal Smartphone and Ecological Momentary Assessment Study. J. Med. Internet Res. 22:e20185. doi: 10.2196/ 20185

Instituto Internacional para la Educación Superior en América Latina y el Caribe (2020). El Coronavirus COVID-19 y la educación superior: Impacto y recomendaciones. Paris: UNESCO.

Instituto Nacional de Estadística e Informática (2021). Pobreza monetaria alcanzó al 30,1\% de la población del país durante el año 2020. Lima: Instituto Nacional de Estadística e Informática.

Islam, M. A., Barna, S. D., Raihan, H., Khan, M. N. A., and Hossain, M. T. (2020). Depression and anxiety among university students during the COVID19 pandemic in Bangladesh: A web-based cross-sectional survey. PLoS One 15:e0238162. doi: 10.1371/journal.pone.0238162
Johnson, M. C., Saletti-Cuesta, L., and Tumas, N. (2020). Emociones, preocupaciones y reflexiones frente a la pandemia del COVID-19 en Argentina. Ciência Saúde Coletiva 25, 2447-2456. doi: 10.1590/1413-81232020256.1. 10472020

Kaparounaki, K., Patsali, M. E., Mousa, D., Papadopoulou, E., Papadopoulou, K., and Fountoulakis, K. N. (2020). University students' mental health amidst the COVID-19 quarantine in Greece. Psychiatry Res. 290:113111. doi: 10.1016/j. psychres.2020.113111

Kretchy, I. A., Asiedu-Danso, M., and Kretchy, J.-P. (2020). Medication management and adherence during the COVID-19 pandemic: Perspectives and experiences from low-and middle-income countries. Res. Soc. Administr. Pharmacy 2020:7. doi: 10.1016/j.sapharm.2020.04.007

Kroenke, K., Spitzer, R. L., and Williams, J. B. W. (2001). The PHQ-9: Validity of a brief depression severity measure. J. General Internal Med. 16, 606-613. doi: 10.1046/j.1525-1497.2001.016009606.x

Kuong, L. E. V., and Concha, A. R. U. (2017). Niveles de ansiedad y la calidad de vida en estudiantes de una Universidad Privada de Arequipa. Adv. Psicol. 25, 153-169. doi: 10.33539/avpsicol.2017.v25n2.351

Ma, Y. F., Li, W., Deng, H. B., Wang, L., Wang, Y., Wang, P. H., et al. (2020). Prevalence of depression and its association with quality of life in clinically stable patients with COVID-19. J. Affect. Disord. 275, 145-148. doi: 10.1016/ j.jad.2020.06.033

Mejia, C. R., Quispe-Sancho, A., Rodriguez-Alarcon, J. F., Ccasa-Valero, L., PonceLópez, V. L., Varela-Villanueva, E. S., et al. (2020). Factores asociados al fatalismo ante la COVID-19 en 20 ciudades del Perú en marzo 2020. Rev. Habanera Ciencias Médicas 19:3233.

Mondal, S. K., Khan, A. G., Ali, M., Ahamed, M. K., and Ahmed, K. (2021). Quality of life among Bangladeshi Youth during the early stage of the COVID19 pandemic: A single-site survey. Public Health Pract. 2:100157. doi: 10.1016/ j.puhip. 2021.100157

Necho, M., Birkie, M., Gelaye, H., Beyene, A., Belete, A., and Tsehay, M. (2020). Depression, anxiety symptoms, Insomnia, and coping during the COVID-19 pandemic period among individuals living with disabilities in Ethiopia, 2020. PLoS One 15:e0244530. doi: 10.1371/journal.pone.0244530

Palgi, Y., Shrira, A., Ring, L., Bodner, E., Avidor, S., Bergman, Y., et al. (2020). The loneliness pandemic: Loneliness and other concomitants of depression, anxiety and their comorbidity during the COVID-19 outbreak. J. Affect. Disord. 275, 109-111. doi: 10.1016/j.jad.2020.06.036

Pan American Health Organization (2020). Americas Region COVID-19 Dashboard. Washington, D.C: Pan American Health Organization.

Pappa, S., Ntella, V., Giannakas, T., Giannakoulis, V. G., Papoutsi, E., and Katsaounou, P. (2020). Prevalence of depression, anxiety, and insomnia among healthcare workers during the COVID-19 pandemic: A systematic review and meta-analysis. Brain Behav. Immun. 88, 901-907. doi: 10.1016/j.bbi.2020.0 5.026

Parrado-González, A. (2020). COVID-19: Factores asociados al malestar emocional y morbilidad psíquica en población española. Rev. Esp. Salud Pública 94:e202006058.

Ping, W., Zheng, J., Niu, X., Guo, C., Zhang, J., Yang, H., et al. (2020). Evaluation of health-related quality of life using EQ-5D in China during the COVID-19 pandemic. PLoS One 15:e0234850. doi: 10.1371/journal.pone.0234850

Plataforma digital única del Estado Peruano (2020). Ayacucho: Descienden cifras de contagios y muertes por Covid-19. Peru: Plataforma digital única del Estado Peruano.

Puthran, R., Zhang, M. W. B., Tam, W. W., and Ho, R. C. (2016). Prevalence of depression amongst medical students: A meta-analysis. Med. Educat. 50, 456-468. doi: 10.1111/medu.12962

Rajkumar, R. P. (2020). COVID-19 and mental health: A review of the existing literature. Asian J. Psychiatry 52:102066. doi: 10.1016/j.ajp.2020.102066

Ribeiro, IJJ. S., Pereira, R., Freire, I. V., de Oliveira, B. G., Casotti, C. A., and Boery, E. N. (2018). Stress and Quality of Life Among University Students: A Systematic Literature Review. Health Professions Educat. 4, 70-77. doi: 10.1016/ j.hpe.2017.03.002

Spitzer, R. L., Kroenke, K., and Williams, J. B. (1999). Validation and utility of a self-report version of PRIME-MD: The PHQ primary care study. Primary Care Evaluation of Mental Disorders. Patient Health Questionnaire. JAMA 282, 1737-1744. doi: 10.1001/jama.282.18.1737

StataCorp (2017). Stata Statistical Software: Release 15. College Station, TX: StataCorp LLC. 
Survey Monkey (1999). Survey Monkey. California: SurveyMonkey. Available online at: https://es.surveymonkey.com/home/?ut_source=header (accessed June 21, 1999).

Taype-Rondan, A., Abbs, E. S., Lazo-Porras, M., Checkley, W., Gilman, R. H., Smeeth, L., et al. (2017). Association between chronic conditions and healthrelated quality of life: Differences by level of urbanization in Peru. Quality Life Res. 26:7. doi: 10.1007/s11136-017-1649-7

Tran, B. X., Nguyen, H. T., Le, H. T., Latkin, C. A., Pham, H. Q., Vu, L. G., et al. (2020). Impact of COVID-19 on Economic Well-Being and Quality of Life of the Vietnamese During the National Social Distancing. Front. Psychol. 2020:565153. doi: 10.3389/fpsyg.2020.565153

Vásquez, G., Urtecho-Osorto, ÓR., Agüero-Flores, M., Díaz Martínez, M. J., Paguada, R. M., Varela, M. A., et al. (2020). Salud mental, confinamiento y preocupación por el coronavirus: Un estudio cualitativo. J. Psychol. 54:e1333. doi: 10.30849/ripijp.v54i2.1333

Verma, S., and Mishra, A. (2020). Depression, anxiety, and stress and sociodemographic correlates among general Indian public during COVID-19. Int. J. Soc. Psychiatry 66, 756-762. doi: 10.1177/0020764020934508

Villarreal-Zegarra, D., Copez-Lonzoy, A., Bernabé-Ortiz, A., Melendez-Torres, G. J., and Bazo-Alvarez, J. C. (2019). Valid group comparisons can be made with the Patient Health Questionnaire (PHQ-9): A measurement invariance study across groups by demographic characteristics. PLoS One 14:e0221717. doi: 10.1371/journal.pone.0221717

Vitorino, L. M., Júnior, G. H. Y., Gonzaga, G., Dias, I. F., Pereira, J. P. L., Ribeiro, I. M. G., et al. (2021). Factors associated with mental health and quality of life during the COVID-19 pandemic in Brazil. BJPsych Open 7:62. doi: 10.1192/bjo. 2021.62

Wang, C., and Zhao, H. (2020). The impact of COVID-19 on anxiety in Chinese university students. Front. Psychol. 22:1168. doi: 10.3389/fpsyg.2020.01168

Wang, C., Wen, W., Zhang, H., Ni, J., Jiang, J., Cheng, Y., et al. (2021). Anxiety, depression, and stress prevalence among college students during the COVID-19 pandemic: A systematic review and meta-analysis. J. Am. Coll. Health J. ACH 2021:1960849. doi: 10.1080/07448481.2021.1960849

Wang, Y., Di, Y., Ye, J., and Wei, W. (2020). Study on the public psychological states and its related factors during the outbreak of coronavirus disease 2019 (COVID-19) in some regions of China. Psychol. Health Med. 0, 1-10. doi: $10.1080 / 13548506.2020 .1746817$

World Health Organization (2020a). Coronavirus. Geneva: World Health Organization.

World Health Organization (2020b). Novel coronavirus (COVID-19) situation. Geneva: World Health Organization.

Yang, L., Lu, X., Yan, B., and Huang, Y. (2020). Prevalence of Incorrect Posture among Children and Adolescents: Finding from a Large Population-Based Study in China. IScience 23:101043. doi: 10.1016/j.isci.2020.101043

Conflict of Interest: The authors declare that the research was conducted in the absence of any commercial or financial relationships that could be construed as a potential conflict of interest.

Publisher's Note: All claims expressed in this article are solely those of the authors and do not necessarily represent those of their affiliated organizations, or those of the publisher, the editors and the reviewers. Any product that may be evaluated in this article, or claim that may be made by its manufacturer, is not guaranteed or endorsed by the publisher.

Copyright (C) 2022 Figueroa-Quiñones, Cjuno, Machay-Pak and Ipanaqué-Zapata. This is an open-access article distributed under the terms of the Creative Commons Attribution License (CC BY). The use, distribution or reproduction in other forums is permitted, provided the original author(s) and the copyright owner(s) are credited and that the original publication in this journal is cited, in accordance with accepted academic practice. No use, distribution or reproduction is permitted which does not comply with these terms. 